microscope. Over the past decade, at moetings and in journals devoted to neuropathology, I have watched with increasing dismay the introduction of this powerful tool to this subject, for I fear that many neuropathologists have not accomplished a satisfactory transition from light to electron microscopy. How many of one's early years are devoted to learning to understand what one sees down a light microscope on a normal, not to mention a pathological, preparation? So is it not reasonable to expect a neuropathologist to undergo a similar period of discipline in electron microscopy of the normal central nervous system? Unlike other tissues, the morphological ramifications of nervous system fine structure are vastfixation still presents innumerable problems, the nature of the extracellular space is a subject in itself, experts still disagree about the identification of the difforent sorts of neuroglia, and the literature on synaptic fine structure is in itself almost overwhelming. Yet the neuropathologist must surely have all this at his finger tips if he is going to make a competent analysis of the pathological changes in his micrographs.

Thus the first two chapters on normal neuronal (Hartmann) and neuroglial (Rosenbluth) fine structure are deceptively brief and lacking in key references. O'Leary et al. use the rabbit for model experimental studies in hereditary ataxia. In an otherwise interesting article, the electron microscopy seems so uncritical. An exhaustive study of exactly comparable sites in normal animals is needed before one can be persuaded that, for example, splitting of the myelin lamellae and glial swelling is strictly a feature of the pathological situation. Terry, on Alzheimer's disease, describes the fine structure of the nourofibrillary tangles with the electron microscope. Kidd first described them as clusters of helical pairs of filaments, but Terry maintains that they are twisted neurotubules: the illustrations surely favour Kidd's interpretation. This article called for a detailed appraisal of the neurofilarnent/neurotubule concept and the related problem of argyrophilia, both unfortunately side-stepped by Terry. McMenemey, incidentally, gives an interesting chapter on present concepts of Alzheimer's disease.

Bornstein describes tissue culture experiments as valuable experimental situations for investigating demyelinating conditions-the pathogenic agents involved in, for example, multiple sclerosis remain baffling. Fspecially interesting is the finding that the application of a demyelinating serum produces an immediate functional block of axon transmission long before there is any visible evidence of demyelination. There is some evidence that the synaptic vesicles that carry the transmitter substance may be interfered with. If so, a completely new approach to the study of multiple sclerosis is foreshadowed.

'There are several interesting chapters on geographic neuropathology. Alpcrs's paper on kuru illustrates the cormplexity of factors involved-cannibalism, for example, and the mode of transmission from mother to offspring. The relation of kuru to scrapie is mentioned: a chapter on scrapie with its enigmatic agent responsible for transmission should have been included in this book.

Other chapters deal with preparative techniques, fluorescence microscopy and the problems of human brain biopsy. The illustrations throughout the book are numerous and of good quality. There is a good author index, but a very inadequate subject index.

E. G. GraY

\section{BOOK OF COMPLICATIONS}

\section{Atom, Man and the Universe}

'Tho Long Chain of Complications. By Hannes Alfvén. Translated by John M. Hoberman. Pp. 110. (W. H. Freeman: San Francisco, June 1969.) 32s.

ON reflecting about the world and space in all their complexity, have you ever wondered where man fits in ? On the one hand, we have the minute atom with its associated electrons, protons and neutrons; on the other, we have the universe, billions of galaxies containing billions of stars. In the centre stands man, trying to understand the atomic microcosm, trying to understand the universe which dwarfs him and most of all trying to understand himself, a living, thinking, sentient being. Between the atom, life and the universe lies a high chain of complicated relations, with modern science gainfully attempting to fit the links of this chain together.

Professor Alfvén tackles man's dilemma by considering modern science advancing on three major fronts-the very large, the very small and the very complicated. The very large is studied by astronomers who are continually worrying about the creation of the universe, the origin of the planet Earth and the Moon, and the problem of exclusiveness - is man alone in the universe? (or what is more to the point, could man ever find out if ho was not alone?). The very small is the world of atoms. Everything is made of atoms and man must strive to understand not only the atom itself and why the nucleons bind together but also why atoms combine with each other forming complex molecules. The very complicated is the spheres of biology and zoology. We are made up of individual atoms, but even if we understood them completely, would it be possible for us to understand why we live, see, think and dic? Could we analyse the problems of our soul and conscience in this "atomic" way? There is also the problem of evolution, with atoms and molecules combining to form living cells and finally producing mankind himself. From dust we came, but is dust our only end ?

Alfvén, looking into the future, tries to predict how man will develop. The ineredible tempo of human history (which has only lasted about 6,000 years) is placed in the context of the ages-long development of the Earth. Will computers and space travel drastically change man's relationship with the world?

Anybody who has at some time puzzled about man's place in the universe will find this book stimulating. Alfvén poses a series of thought provoking questions; only time will provide the answers.

David W. Huahes

\section{VECTOR COURSE}

\section{Vectors}

By John Cunningham. Pp. viii + 158. (Heinemann (Educational): London, July 1969.) Boards, 35s; paper, $18 s$.

This book eovers a typical first course on vectors in a British university. It is a pleasantly presented, readable account with several attractive features, but contains one unsatisfactory chapter.

After introducing vectors as represented by line segments satisfying the parallelogram law, differentiation of vectors, scalar and vector product follow a traditional pattern. The suffix notation and change of basis are quickly introduced and used wherc appropriato in the text. 'The author goes even further when introducing the idea of cartesian tensors. He uses this idea in application to deformations and for the permutation tensor $\varepsilon_{i j k}$. Although the topies in the first half of the book are not particularly well motivated as they are introduced, many of the applications in the text are from clomentary mechanies with two chapters reserved for specific applications to rigid body displacements and deformations. The chapter on displacements looks primarily at the problem of representing both finite and infinitesimal rotations. This is one of the best parts of the book and the illustration of the use of quaterrions for finite rotations, which is both elementary and illuminating, is particularly good. There are few, if any, books at this level that troat doformations and for this reason the chapter on this topis 